\title{
MINE, ALL MINE!
}

Throughout history, gold has been prized around the world and eagerly sought. But where does it come from, and where does it all go? By Neil Savage.

\section{WHERE DOES GOLD COME FROM?}

World gold production 2010

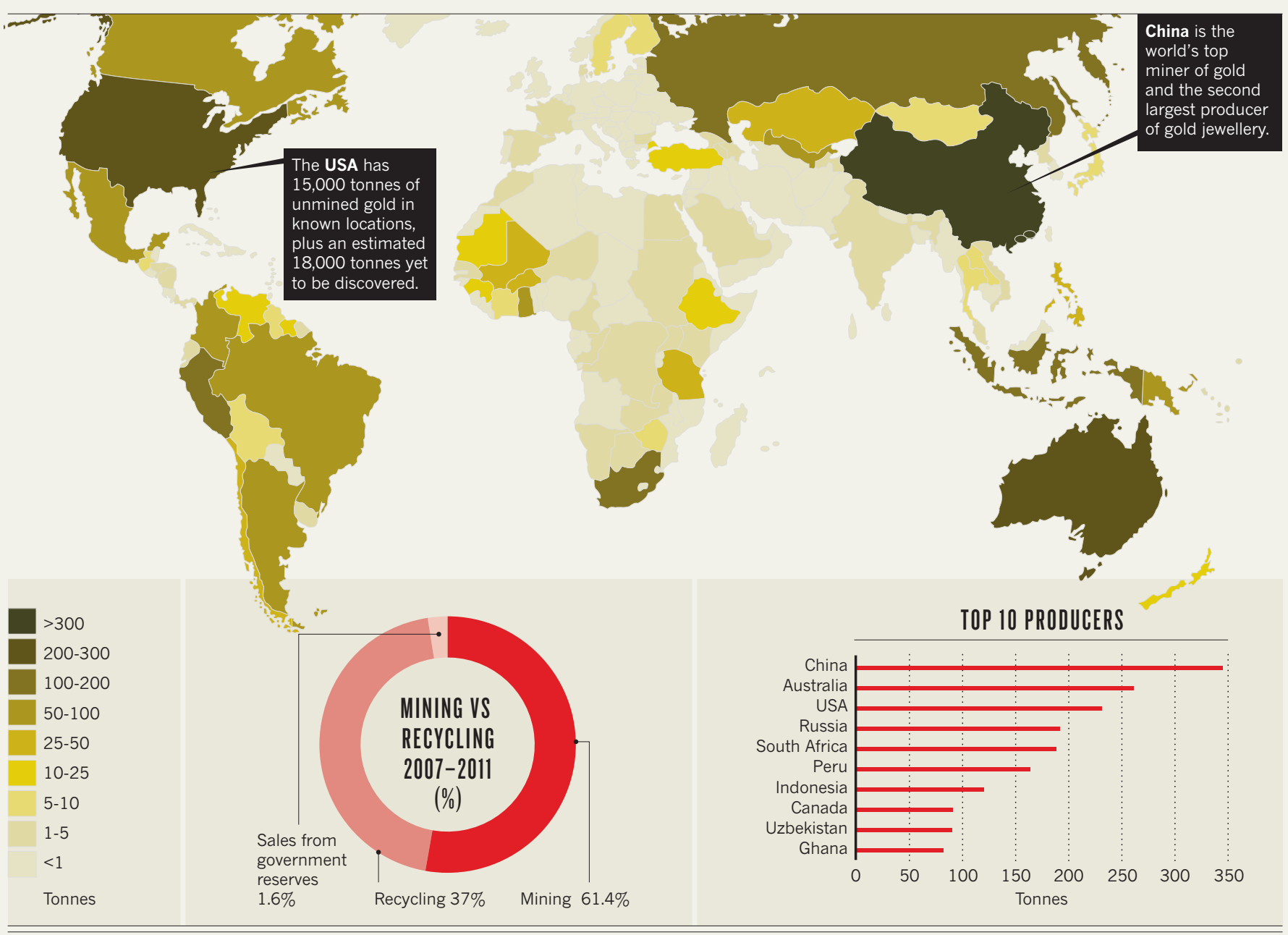

\section{GOLDEN MILESTONES}

Key moments in the use of the precious metal in science and technology

\section{ca. 700}

The Etruscans use gold bands in dentures.

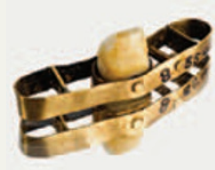

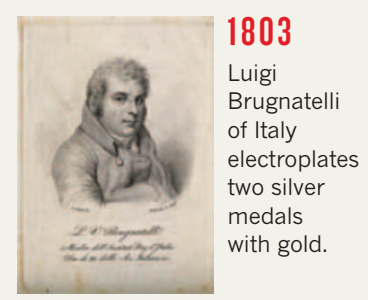

\section{8}

California's Gold Rush starts the extraction of more than $90 \%$ of the gold ever mined.

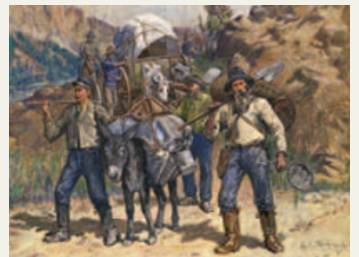

\section{6}

Michael Faraday experiments with suspensions of gold in solution.

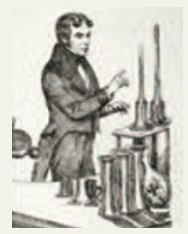

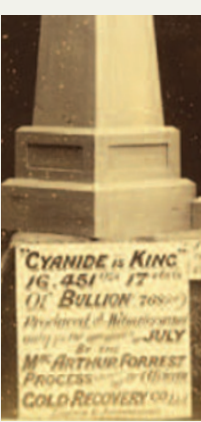

1887

Invention

of the

McArthur-

Forrest

process

using cyanide

to extract

gold from

low-grade ore. 


\section{GOLD IN PERSPECTIVE}

Gold production pales in

comparison to that of other

technologically important

minerals

\section{Aluminium}
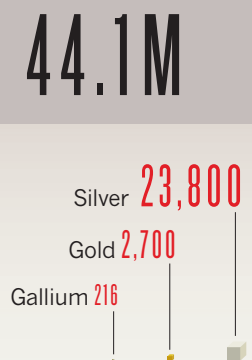

\section{WORLDWIDE DEMAND FOR GOLD IN 2011}

Gold is mostly required for jewellery, technology and money
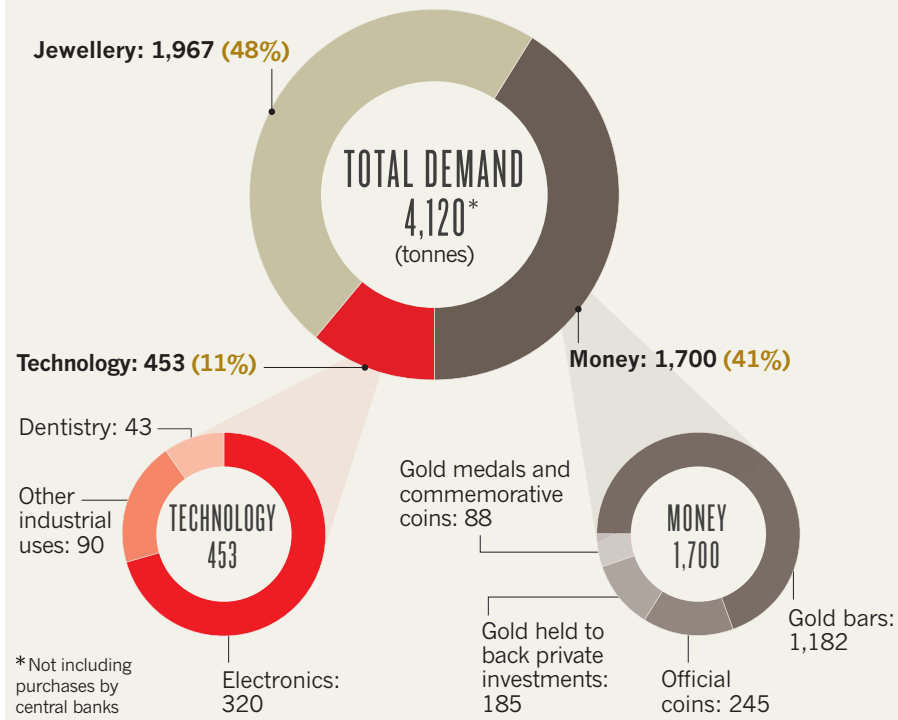

coins: 245

\section{THE PHYSICS OF GOLD}

Electrons orbit the nucleus at half the speed of light, relativistically shrinking the highest-energy (6s) orbital in a way that accounts for gold's chemical stability and hue

Nucleus

contains 79

protons and

118 neutrons

$5 d$ orbital is relativistically enlarged

$6 s$ orbital is relativistically shrunk so this high-energy electron is, on average, closer to the nucleus than are the $5 d$ electrons, making it less available to bind to other atoms

Relativistic effects shrink the energy gap between $5 d$ and $6 s$ electrons so the atom absorbs blue light; what we see is a combination of the other colours in the spectrum, which add up to a golden hue

\section{PRECIOUS COMMODITY}

The price of gold, long set by governments, remained steady from the early eighteenth century well into the twentieth century

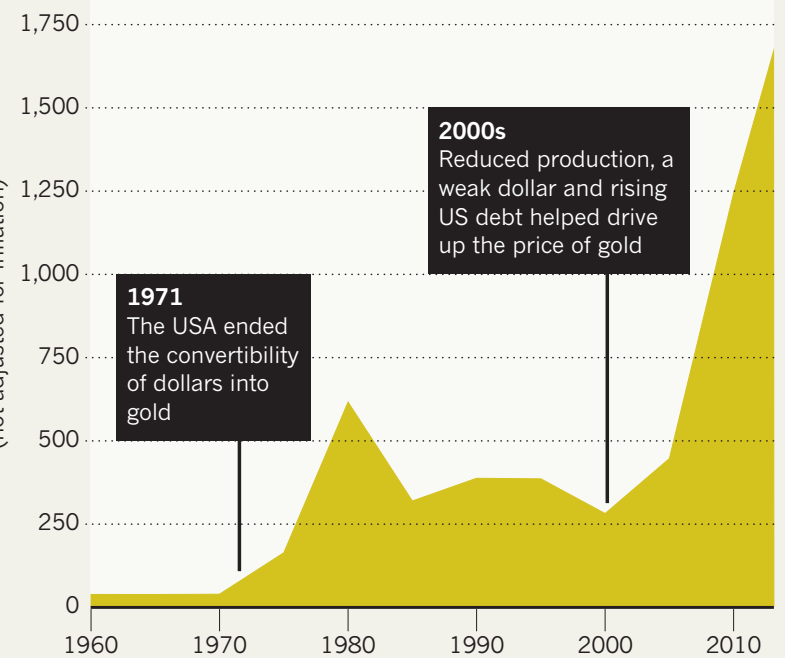

1911

Ernest Rutherford shoots

alphaparticles through gold foil to reveal the existence of the atomic nucleus.

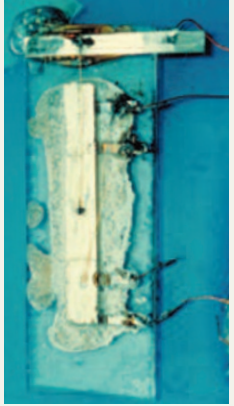

1957

Jack Kilby uses gold wire

connectors in the first integrated circuits.

\section{5-1987}

Masatake Haruta and Graham Hutchings demonstrate the use of gold as a catalyst.

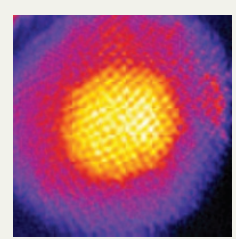

1996

Chad Mirkin and Paul Alivisatos use DNA to build gold nanoparticles.

\section{0}

Boston Scientific starts selling a gold-plated stent for heart surgery.

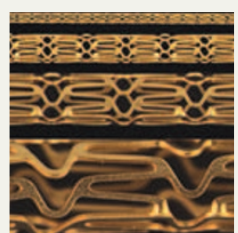

2012

The FDA approves Verigene, a gold nanoparticle diagnostic device to identify infectious bacteria.

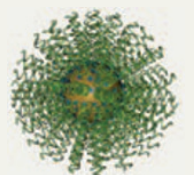

